\title{
LA COLECCIÓN NUMISMÁTICA DEL ANTIGUO MUSEO DE GUADALAJARA: 1838-1902
}

\author{
THE NUMISMATIC COLLECTION \\ OF THE ANCIENT GUADALAJARA MUSEUM: 1838-1902
}

\author{
EMILIO GAMO PAZOS \\ Universidad Complutense de Madrid
}

\begin{abstract}
Resumen: Este estudio aborda la colección de monedas del antiguo Museo de Guadalajara. El conjunto numismático procede de varios yacimientos arqueológicos en los que se realizaron intervenciones en el siglo XIX. El estudio de la documentación relativa a ingresos en este Museo nos ha permitido averiguar el origen de parte de las monedas. Las monedas que aquí tratamos contribuyen al conocimiento de la circulación monetaria en la Antigüedad en la Meseta oriental.

Palabras-clave: Museo de Guadalajara, Numismática, Celtiberia, Checa.
\end{abstract}

\begin{abstract}
This research studies the coin collection of the old Museum of Guadalajara. This numismatic set comes from several archaeological sites in which interventions were made in the nineteenth century. The study of the documentation relating to income in this Museum has allowed us to find out the origin of the coins. The coins here try contribute to the knowledge of monetary circulation in antiquity in the eastern Plateau.
\end{abstract}

Keywords: Guadalajara Museum, Coinage, Celtiberia, Checa.

\section{INTRODUCCIÓN.}

El conjunto numismático que presentamos, inédito hasta ahora, pertenece a la colección del antiguo Museo de Guadalajara ${ }^{1} \mathrm{y}$ fue ingresado entre $1838 \mathrm{y}$ 1902. Abordamos exclusivamente el estudio de la numismática de la Edad Antigua, no de las monedas de cronología medieval, moderna o contemporánea.

El estudio de la documentación conservada en los archivos de Guadalajara, Real Academia de la Historia y Real Academia de Bellas Artes de San Fernando

\footnotetext{
${ }^{1}$ Queremos agradecer al Museo de Guadalajara las facilidades para el estudio de esta colección. A este Museo pertenecen gran parte de las imágenes de las monedas aquí reproducidas. También queremos agradecer a Miguel Ángel López Trujillo su amable ayuda para el estudio de la documentación de la Comisión Provincial de Monumentos en el siglo XIX. Así como a los archivos de Guadalajara, Real Academia de la Historia y Real Academia de Bellas Artes de San Fernando.
} 
alusiva a los ingresos numismáticos en el Museo, en el citado período, permite averiguar el contexto arqueológico de las piezas. El conocimiento del origen de las piezas aporta interesantes datos acerca de la circulación monetaria, intercambios comerciales y rutas de comunicación en la Antigüedad.

La investigación acerca de los aspectos numismáticos en la Antigüedad en Guadalajara tiene un problema de escasez de datos sobre los que obtener conclusiones fiables (Gozalbes 2008: 204). Problema añadido es que son escasos los hallazgos numismáticos efectuados en excavaciones arqueológicas. Muchas de las monedas documentadas de esta cronología proceden de hallazgos fortuitos o excavaciones antiguas en las que el origen no siempre es seguro, así en ocasiones se sabe el nombre de la localidad pero no del yacimiento en concreto del que proceden (Abascal 1984; Vidal 1981).

Por estas razones la búsqueda del contexto arqueológico de las monedas del antiguo Museo de Guadalajara cobra especial interés para el conocimiento de la numismática de este período en esta área.

2. LA COLECCIÓN NUMISMÁTICA DEL MUSEO DE GUADALAJARA A LA LUZ DE LA INFORMACIÓN DOCUMENTAL.

Este Museo fue fundado por la Junta Científica y Artística de Guadalajara (Comisión Provincial de Monumentos desde $1844^{2}$ ) en el año 1838 en el Convento de la Piedad (Aguado 2006: 52). En 1861 la Diputación desmontó el Museo y sus colecciones fueron dispersadas por distintas instituciones, hasta que en 1873 se reubicó en el Palacio del Infantado (Baquerizo 1902: 17). Sin embargo en 1878 el Duque de Osuna vendió el Palacio del Infantado al Ministerio de Guerra para crear un Colegio de Huérfanos, así que la colección se tuvo que desplazar al Convento de la Concepción de Guadalajara, repartiéndose parte de los materiales entre diversas instituciones (Aguado 2006: 53).

En 1899 la techumbre del Convento de la Concepción se derrumbó y se instalaron sus colecciones en el recientemente construido Edificio de la Diputación (Aguado 2006: 53). En este momento Carmelo Baquerizo (1902) realizó un inventario de los materiales del Museo custodiados en la Diputación y otros centros. Baquerizo (1902: 39) describió el conjunto numismático al que nos referimos del siguiente modo: "Numismática. Tres monedas de plata; una del Emperador Trajano, otra de Don Pedro, Rey de Castilla y la otra de Calígula, y además ciento

\footnotetext{
${ }^{2}$ Sobre esta institución se puede ver: López 1997; López y García-Risco 1996.
} 


\section{EMILIO GAMO PAZOS \\ LA COLECCIÓN NUMISMÁTICA DEL ANTIGUO MUSEO DE GUADALAJARA (1838-1902)}

catorce monedas de cobre de diferentes épocas, entre las que se encuentran de Trajano, Antonino Imperial, Adriano, Tiberio, Cesar Augusto, Celsa Municipal, Celtibera, Geta, Turiasu, Cartaginesa, Vespasiano, Segobriga municipal, Bilbilis, Constantino, Col Victix, Benedictina, Escavica, Graciano, Romana Consular, Segisa Celtibérica, Aliga Celtibérica, Victorino, Galba, Maximiano y Focas, no habiendo sido posible hacer la clasificación de las noventa monedas restantes, por las malas condiciones de las mismas".

En 1973 se instaló en el Palacio del Infantado el Museo de Guadalajara, donde permanece hasta la actualidad (B. O. E. 23-VIII-1973). Posteriormente la Diputación ingresó en el Museo esta colección numismática. Se conserva en el Archivo del Museo un documento denominado: "Acta de entrega y recepción de un tesorillo de monedas y otros objetos antiguos, asi como dos terracotas existentes en la sede de la Excma. Diputación Provincial de Guadalajara" (19-VI-1975). En el documento de ingreso se alude a la existencia de 102 monedas, faltando las monedas de plata incluidas en la citada descripción de Baquerizo. Estas monedas fueron ingresadas acompañadas de las etiquetas que tenían en el antiguo Museo, que todavía se conservan.

\section{EL ORIGEN DE LAS PIEZAS.}

Mediante el estudio de documentación de distintos archivos hemos podido rastrear el origen de parte de las monedas de esta colección.

Una parte importante de las monedas procede del término de Checa. En esta localidad realizó excavaciones el párroco Don Faustino Hernando y en 1845 envió a la Comisión Provincial de Monumentos una serie objetos arqueológicos y monedas. De esta entrega existe una memoria, hasta ahora inédita, de cuya existencia nos informó M. A. López Trujillo. El citado documento se conserva en el archivo de la Real Academia de Bellas Artes de San Fernando y describe así las monedas:

Memoria enviada por Rafael de Navascués al presidente de la Comisión Central de Monumentos (Ministro de la Gobernación de la Península), 18 de enero 1845, Guadalajara. (Signatura R. A. S. F. 2-48-3): “(...) He creído oportuno llamar la atención sobre V. E. sobre los descubrimientos notables que se le han denunciado, de escombros y otros objetos encontrados en los términos de los Pueblos de Hijes y Checa, que denotan la existencia de algunas poblaciones antiguas, sin poder hasta ahora designar su época.

Han sido la primera en ponerlos en el conocimiento de esta Comisión, los curas párrocos de los pueblos citados, acordando en consecuencia, excitar su celo y patriotismo para que continuaran en sus investigaciones, proporcionando noticias que en adelante adquirieron. 
No en valde fue hecha la excitación al cura párroco de Checa Don Faustino Hernando, pues al poco tiempo puso en disposición de esta Comisión 42 monedas de plata y cobre, unas armas y, otros objetos del uso de aquella época acompañándola de una memoria que aplica su conocimiento.

Por la adjunta copia de la esperada memoria, podrá conocer V. E. las monedas recogidas y el celo demostrado por el cura párroco de Checa. Para recompensarlo, acordó esta Comisión hacer honorífica mención de su nombre y de este hecho en el Boletín Oficial de la Provincia, dándole al tiempo gracias por su desprendimiento.

(...)Memoria de las cuarenta y dos monedas antiguas que se remiten a la Comisión de Monumentos científicos, históricos y artísticos de la Provincia de Guadalajara $=$ Villa de Checa (...) remito a la Comisión Cuarenta y dos monedas de todos tiempos, encontradas en la Sierra y en el término. Otra porción de armas, de las que nada digo, porque no entiendo, y unas líneas que manifiestan la figura de dos castillos, que tengo vistos y registrados por estar en las cercanías de esta villa. Los de la Sierra, donde se encuentran con más abundancia monedas de plata, de bronce y cobre, chuzos, saetas y otros armamentos, nada digo porque no los he visto, y el tiempo no permite registrarlos y paso a las monedas, sin perjuicio de que la Comisión enmiende mis errores, lo que de ellas digo:

Cartón 1 = Moneda 1 = Cabeza barbada y desnuda, delante dos delfines, detrás otro, por el reverso jinete con caballo que corre, palma en lugar de lanza, morrión y penacho. Debajo letras desconocidas. Esta moneda se aplica a Celsa en el Bajo Aragón a orillas del Ebro y otros la aplican a Sagunto (véase Flórez).

2 = Cabeza desnuda, un delfín por delante y otro por detrás. Por el reverso jinete con caballo que corre, debajo letras desconocidas. Se parece esta moneda a las de arriba.

3 = Cabeza tosca con mucho pelo. Por el reverso un jinete con caballo que corre, no se le nota lanza ni nada por estar mal conservada. Debajo letras desconocidas aunque se parece algo a las romanas.

4 = Cabeza de Hércules, pero sin la piel de león, por detrás se ve una figura como S. Por el reverso una nave y debajo letras desconocidas, la de Carteya (v. Flórez).

5 = Cabeza desnuda y tosca, no se le nota figura alguna. Por el reverso, jinete y caballo que corre, sin notarsele más por mal conservada, en el cantero se notan letras que parecen romanas.

6 = Cabeza tosca y desnuda en el reverso caballo que corre sin freno y jinete sin lanza. Debajo debe decir $<$ Lout $>$ si estuviere bien conservada. Esta es una ciudad que no se sabe dónde existió.

7 = Cabeza de Minerva. En el reverso una columna alta y encima una mujer según parece y las letras C. V. I. N. K. Colonia Insir Victix Nova Kartago.

8 = Cabeza desnuda y al reverso un ciervo o caballo, no se de quién es.

Cartón 2 = Moneda 9 = Cabeza tosca con mucho pelo, detrás caballo que corre y jinete sin notarsele nada por estar mal conservada; debajo letras desconocidas.

$10=$ A esta no se la nota más que el busto.

11 = Ya estamos en el tiempo de los Emperadores. La presente moneda es de Augusto perfectamente conservada y grabada en Celsa. Tiene la cabeza de Augusto en el centro, por delante Augustus, por detrás Divi Filius, en el reverso en el centro un toro, encima L. Sura. Debajo L. Bucone. Por delante dim viris, Por detrás en Cifra Colonia Victris Julia Celsa. 
12 = Cabeza de Augusto. Por delante Colonia Victris Julia Celsa, algo maltratada. Por detrás Augustus todo dentro de una corona de laurel, en el reverso. En el centro un toro con la contramarca R. encima de Cornelio Terreno, debajo M. delante Dum Viris. Está mal conservada.

13 = En el centro cabeza de Augusto por delante, debió decir Augustus, por detrás en letras claras Divi Filius. por el reverso en el centro el Apice, el símpulo y el Asperilio. Con la Segur, y en el contorno unas letras claras que no me atrevo a interpretar. Esta moneda no llegó a manos del M. Flórez.

14 = En el centro cabeza de Augusto, por detrás Augustus, todo lo demás mal tratado, en el reverso, en el centro dos bueyes y debajo un rótulo que parece dice terreno. No se puede decir con conocimiento de donde es.

$15=$ Esta moneda no se puede venir en conocimiento de quién es.

$16=$ Cuando se nota la cabeza de Augusto por lo maltratada que se halló y por el reverso debajo de caballo, se lee claramente Bilbilis.

Cartón 3 = Moneda 17 = Cabeza bien conservada, por el reverso una figura que parece estar sobre una columna, una letra a cada lado, arco y flecha en la mano.

18 = Esta moneda el tiempo ha acabado con ella, es de Augusto en el mismo busto y por el reverso las cabezas de sus nietos, Cayo y Lucio, hijos de Julia y Agripa. Se gravó en Tarragona (V. Fórez).

19 = Cabeza de Tiberio en el centro, en el contorno, Tiberius Augustus Divi Filius Imperator, en el anverso un toro en el centro, encima L. Julio Sparso. Debajo L. Saturnino, delante Dum viris, detrás con cifra Municipium Calagurris Julia.

$20=$ Esta moneda es como la anterior de Calahorra.

21 = Cabeza de Tiberio en el contorno Tiberius Cesar, Divi Filius Augustus Imperator XIII, por el reverso corona de encina y en el centro Secobrica, Segorbe.

22 = Cabeza de Cayo Calígula gastada en el contorno Cayus Cesar, Augustus Germanicus Imperator. Por el reverso, corona de encina y en el centro Secobrica.

23 = Otra como las anteriores, el busto es diferente las letras están gastadas. Por el reverso Secobrica.

24 = Cabeza de Calígula en el centro. En el contorno Cayus Cesar Augustus, Germanicus Pater Patriae, por el reverso, toro con mitra, encima Municipium Ercavica, el contorno, Cayo Terencio. L. Licinio Gracile, detrás Dum viris (V. Flórez).

Cartón 4 = Monedas 25, 26, 27, 28 y 29 = Estas monedas las tengo por de Claudio yo en el centro, su cabeza en el contorno. Tienen en cifra Claudius, Cesar, Augustus Imperator, por el reverso un hombre desnudo con lanza en la mano. A los lados las letras S y C en el contorno, Constancia Augusta, la segunda en el reverso, Libertas Augusta, la cuarta y quinta otra figura con la letra $\mathrm{S}$ y $\mathrm{C}$ al pie.

30 = Esta moneda me es desconocida y de ella no da razón el M. Flórez.

31 = Cabeza de Domiciano con lanza, con el contorno Cesar Augustus Domitianus Cons, no se lee el número, en el reverso un hombre que parece estar desnudo con dardos en la mano y en el contorno Felicitas pública.

$32=$ De esta moneda no puedo entender por su mala conservación.

Cartón 5 = Moneda 33 = Esta moneda es desconocida por mal conservada.

34 = Esta es del Emperador, centro cabeza del mismo, detrás Gordianus. Por el reverso un guerrero con arco y flecha y vestidura larga con varias letras.

35 = En el centro cabeza de Gordiano con laurel, en el contorno Imperator Gordianus Pius Felix Augustus, por el reverso un hombre desnudo con una bola en la mano izquierda con una letra en cada lado, y en el contorno Eternitas Augusta. 
36 = Cabeza de Vespasiano, todo el contorno escrito pero no se puede leer más que Pasianus esto es Vespasianus. Por el reverso un hombre sentado que apoya la mano derecha sobre la lanza y otras figuras.

Cartón $6=$ Moneda $37=$ Desconocida por mal conservada.

38 y 39 = Cabeza de Constantino con lanza, en el contorno Constantinus Augustus, en el reverso en el centro un edificio en la primera y en el contorno Providencia Augusta, en la otra hombre desnudo con rótulo.

$40=$ Desconocida.

Cartón $7=$ Moneda $41=$ Esta preciosa moneda fue encontrada con la lumbre de una viuda de esta villa y sin duda debió venir de la raíz de algún pino o tea está grandemente conservada, es de plata y más preciosa que de plata por ser de los Emperadores más famosos que tuvo Roma y más que todo esto por ser Español. Ocupa el centro de la Cabeza de Trajano con lanza y en el contorno dice imperator, Cesar Nerva Trajanus Augustus Germánicus y en el reverso ocupa el centro una figura de hombre sobre su basa, con los brazos tendidos y en la mano una cosa larga debajo del brazo izquierdo otra cosa redonda y en el contorno unas letras que parecen iniciales.

42 = Centro la Corona y debajo una P. por el contorno Dominus mihi adiutor lo que sigue parece abreviado, y en otro contorno más interno comienza unas letras que no se pueden unir. por el reverso en el centro Castillos y leones, y en el contorno Petrus Rex Castela et Legioni.

Entre las que me quitó la facción había de Setabi, Ghracurris, Clunia y otras muchas ciudades y de plata con el busto de una Emperatriz, Águilas Romanas y los signos legionarios. Estas encontradas en los Castillejos de la Sierra.

Al medio día de esta villa y un corto paseo de ella, se halla un cerro llamado Castillo de Griegos y en lo más encumbrado las minas de un Castillo antiguo en donde se hallan monedas de la más remota Antigüedad. El muro de este Castillo, tiene tres varas de espesor, 42 de latitud y 19 de amplitud. Tiene un foso que le rodea por la parte de oriente y medio día, no necesitándolo por la parte de poniente y norte por rodearlo una caja de piedras que hace imposible la subida y por donde aquellas no la defienden, esta es sumamente empinada. En la parte que el foso forma ángulo, nace otro construido en piedra viva, que divide el Castillo en dos. El foso está retirado del Castillo 14 varas, tiene de ancho nueve, a su borde tiene una muralla que va a enlazarse con la vista y forma una gran plaza que tiene 30 varas de ancho, 54 de largo y 54 de murallón. En la Dehesa llamada Cubillo se encuentra otro Castillo construido de piedra labrada y sus paredes de bastante espesor. Está rodeado de un foso picado en piedra viva y todo él está en buen estado de defensa, tiene tres entradas pequeñas y ninguna por alto lo que induce a creer que debieron ser subterráneas".

Las excavaciones del párroco de Checa fueron mencionadas en otros documentos de la Comisión Provincial de Monumentos agradeciendo su celo y animándole a continuar sus pesquisas.

En la Memoria acerca de los hallazgos de Checa se alude a tres yacimientos arqueológicos: "Castil Griegos", "El Cubillo" y "Castillarejos", castros datados en las últimas fases de la cultura celtibérica (Arenas 1999: 109). Estos enclaves celti- 


\section{EMILIO GAMO PAZOS \\ LA COLECCIÓN NUMiSMÁtICA DEL ANTIGUO MUSEO DE GUADALAJARA (1838-1902)}

béricos tienen continuidad hasta época romana. Castil Griegos es un castro rodeado de muralla de paramento ciclópeo y foso. Este enclave es conocido desde antiguo y citado en el siglo XVII por D. Sánchez Portocarrero (1641). El poblado de "Castil Griegos" y su correspondiente necrópolis de "Puente de la Sierra" fueron excavados en sucesivas campañas de excavación desde 2005, bajo la dirección de J. P. Martínez y J. I. de la Torre (2008).

Como se puede ver en la descripción del conjunto numismático parte de las monedas descritas en la citada Memoria pueden identificarse con las actualmente existentes. Sin embargo, tenemos constancia de que algunas de las monedas descritas ingresaron en el Museo pero se perdieron con posterioridad a 1902. Se trata de un denario de Trajano y una moneda de plata del rey Pedro de Castilla $\left(n^{\circ} 41\right.$ y 42 de la Memoria), a las que aludía Baquerizo (1902: 39). El denario de Trajano perdido se puede identificar por la descripción de la Memoria, con los denarios que representan en el anverso una cabeza laureada a derecha y la leyenda IMP CAES NERVA TRAIAN AVG GERM, en el reverso Hércules desnudo sobre un altar, puede corresponder con RIC II, 37, 49 o 79.

Entre las monedas que tuvo el párroco de Checa y no llegaron a ingresar el Museo en la Memoria se describen monedas procedentes de "Castillarejos" de las cecas de Setabi, Gracurris, Clunia y un denario romano.

En la Memoria de Checa se alude a una serie de monedas de bronce que estaban ya desaparecidas en 1975, pero que son claramente identificables. Son las $\mathrm{n}^{\mathrm{o}}$ 11, 12, 19 y 24 de la Memoria. La n ${ }^{\circ} 11$ es un As de Celsa, de época de Augusto, en el anverso cabeza a derecha y leyenda: AVGVSTVS-DIVI F. En el reverso toro a derecha, leyenda: C V I CEL/ L SVRA/ L BVCCO/ II VIR. Se corresponde a Ripollès 2010: 191, $\mathrm{n}^{\circ}$ 271. En el inventario de Baquerizo (1902: 39) se alude a monedas de "Celsa municipal". La no 12 de la Memoria es otro As de Celsa, de época de Augusto, en el anverso cabeza a derecha dentro de una corona, leyenda: AVGVS(TVS)-C V I CELS(A). En el reverso toro a derecha, leyenda: L COR(NE) TER(RENO)/ M IVN(I) HIS(PANO)/ II VIR. Se corresponde a Ripo1lès 2010: 189, $\mathrm{n}^{\mathrm{o}}$ 270. La $^{\circ} 19$ de la Memoria es un As de Calagurris, de época de Tiberio, en el anverso cabeza laureada a derecha, leyenda: TI AVGVS DIVI AVGVSTI F IMP CAESAR. En el reverso toro a derecha, leyenda: M C I/ L FVL SPARSO/ L SATVRNINO/ II/ VIR. Se corresponde a Ripollès 2010: 268, nº 448. $\mathrm{La}^{\circ} 24$ de la Memoria es un As de Ercavica, de época de Calígula, en el anverso cabeza laureada a derecha, leyenda: C CAESAR AVG GERMANICUS P P. En el reverso toro con mitra a derecha, leyenda: MVN/ ERCAVICA/ C TER SVRA ET 


\section{EMILIO GAMO PAZOS \\ LA COLECCIÓN NUMismÁtiCA DEL ANTIGUO MuSEO DE GUADALAJARA (1838-1902)}

L LIC GRACILE II VIR. Se corresponde a Ripollès 2010: 281, n 466. En el inventario de Baquerizo (1902: 39) se alude a una moneda de "Escavica".

Se tiene constancia de otra entrada de monedas procedentes de las excavaciones en la villa romana de "Los Arroyos" (Hijes), excavada al tiempo que la necrópolis celtibérica situada junto a ella. En Hijes se realizaron cuatro campañas durante los años 1840, 1845, 1850 y 1912, esta última dirigida por el marqués de Cerralbo (Aguilera y Gamboa 1916: 31, 58; Cerdeño y Gamo 2013). Se menciona su existencia en la correspondencia -conservada en la Real Academia de Bellas Artes de San Fernando-que mantuvo la Comisión Central de Monumentos con su Sección en Guadalajara, en la que aparecen mencionadas las excavaciones realizadas por el párroco de la localidad en los años 1840 y 1845 (Gómez-Pantoja y López 2004: 153-160).

Concretamente tenemos la descripción de tres monedas (no sabemos si pudieron ingresar más) procedentes de Hijes mencionadas en una misiva de la Comisión de Guadalajara a la Central, (R. A. B. A. S. F. 2-48-3) de 3 Junio de 1846: "el mismo Sr. Cura ha remitido a esta Comisión con posterioridad, tres monedas halladas en dicha excavación, dos del Emperador Graciano y otra de Constantino, Pio, Félix, Augusto" (Gómez-Pantoja y López 2004: 158). Hay que destacar que entre la colección de monedas que tratamos se conservan efectivamente dos monedas de Graciano ( $\mathrm{n}^{\circ} 44$ y 51 ). A este ingreso de monedas aludió también José Julio de la Fuente (1883: 169): "En el mismo año 1845 (...) tuvo también lugar e hallazgos de algunas monedas romanas en las excavaciones practicadas en el pueblo de Hijes, cuyo párroco D. Pedro Pereda, ofreció remitirlas a la Comisión Provincial, como lo verificó". Estas monedas, a diferencia de las medievales del Castillo de Zorita, que fueron al monetario de la Biblioteca Nacional, no salieron del Museo de Guadalajara (De la Fuente 1883: 169).

En 1850 Francisco Nicolau y Bofraul, delegado provincial del gobierno, realizó excavaciones en la necrópolis celtibérica de Hijes, no así en la villa romana cercana, de modo que no se encontraron monedas como se menciona en una comunicación de 24 de Abril de 1850 (R. A. B. A. S. F. 2-48-3): “(..) y demás efectos hallados, sin inscripción, moneda, figura o estatua ni otro vestigio que atestigüe la época de su construcción" (Gómez-Pantoja y López 2004: 158). Siendo los materiales de la excavación de 1850 donados posteriormente al M. A. N.: "Excitado por Real orden-circular de 6 de Noviembre de 1867 el celo de las Comisiones provinciales de Monumentos para que remitiesen al Museo Arqueológico Nacional que acababa de crearse, objetos de antigüedad, a fin de que en el estuviesen representadas todas las provincias de España, la de Guadalajara re- 


\section{EMILIO GAMO PAZOS \\ LA COLECCIÓN NUMISMÁTICA DEL ANTIGUO MUSEO DE GUADALAJARA (1838-1902)}

mitió en Abril de 1868 las armas, capacetes y vasijas de barro descubiertas en Hijes en 1850..." (De la Fuente 1883: 173). Sin embargo, en este lote no se incluían las monedas halladas con anterioridad, que continuaron en el Museo de Guadalajara, como se observa en la relación de objetos entregados (Comunicación de Florencio Janer, Gobernador civil de Guadalajara al M. A. N., 1-IV-1968, Archivo M. A. N. Legajo 1868-103A): "3 capacetes de hierro; 40 hierros de lanza, cuchillos, etc; 8 vasijas llenas de huesos y tierra; 2 pequeñas bolas y 2 pequeños discos de barro; 4 alambres enroscados; 2 especies de fibulas o acaso pendientes de metal hallado todo en las vasijas con huesos y barro rotas de la propia procedencia; fragmentos de vasijas, alambres y trozos de hierro" (Gómez-Pantoja y López 2004: 159).

En la Real Academia de la Historia se conserva abundante documentación acerca de los hallazgos numismáticos en las obras del ferrocarril Madrid-Zaragoza en 1859, sin embargo las monedas que se mencionan no llegaron nunca al Museo de Guadalajara sino que fueron enviadas directamente a la Real Academia de la Historia. Tal y como se ordenaba por parte de la Real Academia 3. "En 1 de Abril de 1859 trasladó a esta Academia el Señor Ministro de Fomento la Real orden dirigida con igual fecha al Gobernador de Guadalajara para encargando la conservación de cuantas antigüedades se descubrieran en las excavaciones del ferrocarril de Madrid-Zaragoza, mandando depositar en las casas consistoriales de los pueblos más próximos las piedras con inscripciones que llegasen a parecer, remitir a esta Academia los pequeños objetos antiguos, y darle noticia de todo descubrimiento, como encargada de velar por la conservación de los Monumentos Históricos" (Meier 1999: 69). De este modo en el Archivo de Guadalajara (Comisión de Monumentos I) se conserva una misiva (Madrid, 31-VII-1867) del Ingeniero Jefe del Cuerpo Nacional de Ingenieros de Caminos, Canales y Puertos (División de ferrocarriles), al Gobernador de Guadalajara en la que le informa de que: “...debo manifestarle que efectivamente se encontraron vestigios de antigüedades romanas al hacer las explanaciones para el ferrocarril de Zaragoza, en el trozo de Guadalajara a Jadraque, y que el señor Rodríguez Arroquias, ingeniero al servicio de la construcción, remitió por conducto de esta División en 26 de Octubre de 1860 a la Real Academia de la Historia, un cajón con diversos efectos, cuya relación se adjunta".

\footnotetext{
${ }^{3}$ Madrid, 4-IV-1868: "Minuta de oficio en la que se comunica dictamen de Real Academia de la Historia sobre las antigüedades descubiertas en las obras de la línea de ferrocarril MadridZaragoza, solicitado por la Dirección General de Instrucción Pública", Signatura: CAGU/9/7956/4(23).
} 


\section{EMILIO GAMO PAZOS \\ LA COLECCIÓN NUMISMÁTICA DEL ANTIGUO MUSEO DE GUADALAJARA (1838-1902)}

Francisco R. de Uhagón realizó hallazgos numismáticos durante sus excavaciones en la villa romana de Gárgoles de Arriba, aunque estas monedas no fueron a parar al Museo de Guadalajara y si quizás a la Real Academia de la Historia, pues su descubridor afirmó al respecto (Uhagón 1893: 350): "Como entiendo que dichos objetos han de despertar el interés de la Academia, me creo en el caso de ofrecérselos para que los disfrute".

Otra fuente de información son las etiquetas que acompañaban a las monedas, pero en casi ningún caso se explicita la procedencia, únicamente en el caso de la moneda $\mathrm{n}^{\circ} 49$ en la que indica que procede de Alaminos: "Alaminos $/ n \%$ De Urbana/ Concordia Militum".

\section{DESCRIPCIÓN DE LAS PIEZAS.}

A continuación se estudian las monedas según $\mathrm{n}^{\mathrm{o}}$ de inventario del Museo. Las monedas medievales, contemporáneas o ausentes se omiten del inventario. Siguiendo las normas de los Monumenta Linguarum Hispanicarum (Untermann 1997) transcribimos en negrita minúscula las leyendas en signarios paleohispánicos.

1. Semis. Ceca: Carthago Nova. Cronología: Segunda mitad siglo I a. C. ${ }^{4}$. A: Cabeza de Minerva a derecha. R: Estatua sobre pedestal, a los lados leyenda CV-IN. Peso: $7 \mathrm{~g}$. Referencia: Ripollès 2010: $\mathrm{n}^{\circ} 151$. Procedencia: Checa $\mathrm{n}^{\circ} 7$.

2. Semis. Ceca: Kese. Cronología: Siglos II a. C. A: Cabeza a derecha. R: Jinete a derecha, debajo leyenda: kese. Peso: 4 g. Referencia: Villaronga 1994: 158-171. Procedencia: Desconocida.

3. As. Ceca: Kelse. Cronología: Posterior al 133 a. C. A: Cabeza a derecha con dos delfines delante y otro detrás. R: Jinete con palma a derecha, debajo sobre línea leyenda: kelse. Peso: 15 g. Referencia: Villaronga 1994: 223, no 11. Procedencia: Checa $\mathrm{n}^{\circ} 1$.

4. Sestercio. Ceca: Roma. Cronología: Vespasiano, año 71 d. C. A: Cabeza laureada a derecha, leyenda: IMP CAES VESPASIAN AVG P M TR P P P COS III. R: A la izquierda Vespasiano poniendo el pie sobre un casco, porta una lanza, en el medio una palmera, a la derecha una mujer; leyenda: IVDAEA CAPTA/ S. C. Peso: 22 g. Referencia: RIC II, 427. Procedencia: Checa ${ }^{\circ} 36$.

5. Dupondio o As. Ceca: Roma. Cronología: 132-134 d. C. A: Cabeza a derecha, leyenda: HADRIANVS AVGVSTVS. R: Galera a izquierda, leyenda ilegible. Peso: $12 \mathrm{~g}$. Referencia: RIC II, 719. Procedencia: Desconocida.

\footnotetext{
${ }^{4}$ Abascal (2002: 24) propuso para esta pieza una cronología en época de Tiberio, en base a la mención del nombre de la colonia. Sin embargo Ripollès (2010: 125) dice que los tipos y factura de los cospeles hacen más coherente asociarla a las emisiones iniciales.
} 


\section{EMILIO Gamo Pazos \\ LA Colección numismática del ANTiguo Museo de GuAdALAJARa (1838-1902)}

6. As. Ceca: Iltirta. Cronología: Posterior al 104 a. C. A: Cabeza a derecha, dos delfines delante y uno detrás. R: Jinete a derecha con capa y clámide, debajo inscripción: Iltirta. Peso: 12 g. Referencia: Villaronga 1994: 178, $\mathrm{n}^{\circ}$ 22. Procedencia: Desconocida.

7. As. Ceca: Iltirta. Cronología: Finales siglo III a. C.-I a. C. A: Cabeza a derecha. R: Loba a derecha, leyenda: iltirta. Peso: 10 g. Referencia: Villaronga 1994: 175-182. Procedencia: Desconocida.

8. As. Ceca: Ikalkusken. Cronología: Mediados siglo II a. C. A: Cabeza a derecha, detrás delfín. R: Jinete lancero con escudo, leyenda: Ikalkusken. Peso: 8 g. Referencia: Villaronga 1994: $325, n^{\circ} 6$. Procedencia: Desconocida.

9. As. Ceca: Roma. Cronología: Adriano, años 125-128 d. C. A: Cabeza laureada a derecha, leyenda: HADRIANVS AVGVSTVS. R: Minerva a derecha con lanza y escudo, leyenda: COS III/ S. C. Peso: 10 g. Referencia: RIC II, 664. Procedencia: Desconocida.

10. As. Ceca: Segobriga. Cronología: Tiberio o Calígula. A: Cabeza de emperador a izquierdas. R: Leyenda SEGO/BRIGA dentro de una corona de roble. Peso: $8 \mathrm{~g}$. Referencia: Ripollès 2010: $n^{\circ} 473$ o no 476. Procedencia: Posible Checa n 21 o 23.

10. B. Sestercio. Cronología: Años 178-179 d. C. A: Cabeza barbada a derecha, leyenda: M. AVREL. ANTONINVS AVG. TR. P. XXXIII. R: Felicitas a izquierda portando caduceo y cetro, leyenda: [FELICITAS AVG. IMP. VIII. COS. III. P. P.]/ S. C. Peso: 22 g. Referencia: RIC III, 1237. Procedencia: Desconocida.

11. Follis. Ceca: Ticinum. Cronología: Constantino I. A: Cabeza laureada con coraza a derecha, leyenda: CONSTANTINVS P F AVG. R: Sol a izquierda, portando globo en la mano izquierda, leyenda: SOLI INVI-C-TO COMITI, en el exergo ST. Peso: 4 g. Referencia: RIC VII, 3. Procedencia: Desconocida.

12. As. Ceca: Indeterminada. Cronología: Siglos II-I a. C. A: Cabeza a derecha, delante dos delfines, detrás otro. R: Jinete con palma a derecha, leyenda ilegible. Peso: $12 \mathrm{~g}$. Procedencia: Desconocida.

13. Semis. Ceca: Indeterminada. Cronología: Siglos II-I a. C. A: Cabeza a derecha. R: Caballo corriendo a derecha, leyenda ilegible. Peso: 6 g. Procedencia: Desconocida.

14. As. Ceca: Indeterminada. Cronología: Siglos II-I a. C. A: Cabeza a derecha. R: Jinete a derecha, leyenda ilegible. Peso: 8 g. Procedencia: Desconocida.

15. No existe.

16. As. Ceca: Caesaraugusta. Cronología: Augusto. A: Cabeza laureada a derecha, a la izquierda simpulum y a la derecha lituo, leyenda: AVGVSTVS-DIVI F. R: Sacerdote arando con yunta de bueyes a derecha, leyenda: CAESAR. AVG(usta)/ MN KANINIO ITER L. TITIO/ II VIR. Peso: 8 g. Referencia: Ripollès 2010: $\mathrm{n}^{\mathrm{o}} 322$. Procedencia: Checa $\mathrm{n}^{\mathrm{o}} 14$.

17. Semis. Ceca: Imitación hispánica de semis romano republicano. Cronología: Siglo I a. C. A: Cabeza de Saturno a derecha, detrás: S. R: Proa de nave a derecha, encima S, 
debajo leyenda: ROMA. Peso: 6 g. Referencia: Villaronga 1994: 427, ${ }^{\circ}$ 2. Procedencia: Checa, $n^{\circ} 4$.

18. As. Ceca: Turiaso. Cronología: Tiberio. A: Cabeza laureada a derecha, leyenda: TI CAESAR AVGVST F IMPERAT. R: Toro a derecha, leyenda: MVN TVR/ C CAEC SER(e)/ M VAL QVAD/ II/ VIR. Peso: 16 g. Referencia: Ripollès 2010: $n^{\circ} 417$. Procedencia: Desconocida.

19. As. Ceca: Bilbilis. Cronología: Augusto. A: Cabeza de Augusto a derecha, leyenda perdida: [AVGVSTVS-DIVI F.]. R: Jinete con lanza a derecha, leyenda: BILBILIS. Peso: 8 g. Referencia: Ripollès 2010: $\mathrm{n}^{\circ}$ 390. Procedencia: Checa $\mathrm{n}^{\circ} 16$.

20. As?. Cronología: Altoimperial. A: Cabeza a derecha. R: Cabeza a derecha con contramarca. Peso: 10 g. Procedencia: Desconocida.

21. As. Ceca: Roma. Cronología: Claudio. A: Cabeza a izquierda, leyenda: TI CLAVDIVS CAESAR AVG PM TR P IMP. R: Minerva a derecha con lanza y escudo, leyenda: S. C. Peso: 12 g. Referencia: RIC I, 100. Procedencia: ¿Checa 28-29?.

22. As?. Cronología: Altoimperial. A: Cabeza a izquierda, leyenda ilegible. R: Totalmente deteriorado. Peso: 8 g. Procedencia: Desconocida.

23. As. Ceca: Roma. Cronología: Claudio. A: Cabeza a izquierda, leyenda: TI CLAVDIVS CAESAR AVG PM TR P IMP. R: Minerva a derecha con lanza y escudo, leyenda: S. C. Peso: 8 g. Referencia: RIC I, 100. Procedencia: ¿Checa 28-29?

24. As. Ceca: Roma. Cronología: Claudio. A: Cabeza a izquierda, leyenda: TI CLAVDIVS CAESAR AVG PM TR P IMP. R: Minerva a derecha con lanza y escudo, leyenda: S. C. Peso: 10 g. Referencia: RIC I, 100. Procedencia: ¿Checa 2829 ?.

25. As. Ceca: Roma. Cronología: Claudio. A: Cabeza a izquierda, leyenda: TI CLAVDIVS CAESAR AVG CAESAR AVG P M TR P IMP P P. R: Constancia a izquierda, leyenda: CONSTANTIAE AVGVSTI/ S-C. Peso: 10 g. Referencia: RIC I, 111. Procedencia: Checa $\mathrm{n}^{\circ} 25$.

26. As. Ceca: Roma. Cronología: Claudio. A: Cabeza a izquierda, leyenda: TI CLAVDIVS CAESAR AVG PM TR P IMP. R: Minerva a derecha con lanza y escudo, leyenda: S. C. Peso: 10 g. Referencia: RIC I, 100. Procedencia: ¿Checa 28$29 ?$.

27. As. Ceca: Roma. Cronología: Claudio. A: Cabeza a izquierda, leyenda: TI CLAVDIVS CAESAR AVG P M TR P IMP [...?]. R: Libertas a derecha, leyenda: LIBERTAS AVGVSTA/ S. C. Peso: 10 g. Referencia: RIC I, 97 o 113. Procedencia: ¿Checa $n^{\circ} 26-27 ?$.

28. A. As. Ceca: Roma. Cronología: Claudio. A: Cabeza a izquierda, leyenda: TI CLAVDIVS CAESAR AVG P M TR P IMP [...?]. R: Libertas a derecha, leyenda: LIBERTAS AVGVSTA/ S. C. Peso: 8 g. Referencia: RIC I, 97 o 113. Procedencia: ¿Checa $\mathrm{n}^{\mathrm{o}} 26-27 ?$. 
28. B. Dupondio. Ceca: Roma. Cronología: Calígula. A: Cabeza a izquierda, leyenda: DIVVS AVGVSTVS/ S. C. R: Calígula togado sentado a izquierda sobre silla curul sosteniendo rama en su mano derecha, leyenda: CONSENSV SENAT ET EQ ORDIN P Q R. Peso: 14 g. Referencia: RIC I, 56. Procedencia: Desconocida.

29. As. Ceca: Ikalkusken. Cronología: Mediados siglo II a. C. A: Cabeza a derecha, detrás delfín. R: Jinete lancero con escudo, bajo línea: Ikalkusken. Peso: 9'5 g. Referencia: Villaronga 1994: 325, $\mathrm{n}^{\circ}$ 6. Procedencia: Desconocida.

30. As. Ceca: Lugdunum. Cronología: Nerón. A: Cabeza a izquierda, leyenda: NERO CLAVD CAESAR AVG GER P M TR P IMP P P. R: Victoria a izquierda, portando un escudo, a los lados leyenda: S C. Peso: 8 g. Referencia: RIC I, 478. Procedencia: Desconocida.

31. As?. Cronología: Altoimperial. A: Cabeza a derecha. R: Figura femenina muy deteriorada. Peso: 10 g. Procedencia: Desconocida.

32. As. Claudio. Ceca: Roma. Cronología: Claudio. A: Cabeza a izquierda, leyenda: TI CLAVDIVS CAESAR AVG P M TR P IMP [...?]. R: Libertas a derecha, leyenda: LIBERTAS AVGVSTA/ S. C. Peso: 8 g. Referencia: RIC I, 97 o 113. Procedencia: ¿Checa $n^{\circ}$ 26-27?.

33. Sestercio. Ceca: Roma. Cronología: Faustina I. A: Cabeza femenina a derecha, leyenda: FAVSTINA AVG ANTONINI AVG PII P P. R: Venus a derecha, leyenda: VENERI AVGVSTAE/ S. C. Peso: 11 g. Referencia: RIC III, 1081. Procedencia: Desconocida.

34. Dupondio. Ceca: Lugdunum. Cronología: Nerón. A: Cabeza a derecha, leyenda: IMP NERO CAESAR AVG P M[...]. R: Securitas sentada a derecha, leyenda: SECVRITAS AVGVSTI/S.C. Peso: 11 g. Referencia: RIC I, 596 o 598. Procedencia: Desconocida.

35. As. Ceca: Lugdunum. Cronología: Nerón. A: Cabeza a derecha, leyenda: [IMP NERO CAESAR AVG PM TR POT PP?]. R: Victoria a izquierda con escudo con leyenda: [S. P. Q. R.], a los lados S. C. Peso: 8 g. Referencia: RIC I, 541. Procedencia: Desconocida.

36. Sestercio. Cronología: Adriano. A: Cabeza a derecha, leyenda: IMP CAESAR TRAIANVS HADRIANVS AVG. R: Muy deteriorado. Peso: 20 g. Procedencia: Desconocida.

37. As. Ceca: Belikio. Cronología: Primer tercio del siglo I a. C. A: Cabeza barbada a derecha. R: Jinete lancero a derecha, sobre línea inscripción: belikiom. Peso: $10 \mathrm{~g}$. Referencia: Villaronga 1994: 214, $\mathrm{n}^{\circ}$ 8. Procedencia: Desconocida.

38. As. Ceca: Cástulo. Cronología: Finales siglo III-II a. C. A: Cabeza a derecha. R: Esfinge a derecha, leyenda ilegible. Peso: 10 g. Referencia: Villaronga 1994: 330-337. Procedencia: Desconocida.

39. As. Ceca: Roma. Cronología: Domiciano. A: Cabeza a derecha, leyenda: IMP CAES DOMIT AVG GERM COS [...?]. R: Virtus a derecha, leyenda: VIRTVTI AVGVSTI/ 


\section{EMILIO GAMO PAZOS \\ LA COLECCIÓN NUMiSMÁTICA DEL ANTIGUO MuSEO DE GUADALAJARA (1838-1902)}

S. C. Peso: 8 g. Referencia: Posibles RIC II (2007), 500 o 550 o 650 o 709. Procedencia: Desconocida.

40. As. Ceca: Roma. Cronología: Adriano, años 132-134 d. C. A: Cabeza a derecha, leyenda: HADRIANVS AVGVSTVS. R: Figura femenina sentada a izquierda (justicia), leyenda: [IVSTITIA AVG. COS. III. P. P./ S. C.]. Peso: 10 g. Referencia: RIC II, 727. Procedencia: Desconocida.

41. As?. Cronología: Altoimperial. A: Cabeza a derecha. R: Figura a izquierda, leyenda: [S] C. Peso: 12 g. Procedencia: Desconocida.

42. As?. Cronología: Altoimperial. A: Cabeza a derecha. R: Muy deteriorado. Peso: $10 \mathrm{~g}$. Procedencia: Desconocida.

43. Sestercio. Ceca: Roma. Cronología: 197-198 d. C. A: Cabeza laureada y barbada a derecha, leyenda muy deteriorada: [L. SEPT. SEV. PERT. AUG. IMP. X]. R: Genio desnudo a izquierda, en la mano derecha lleva una pátera sobre un altar, leyenda muy deteriorada: [P. M. TR. P. V COS. II P. P.] S. C. Peso: 18 g. Referencia: RIC IVA, 743. Procedencia: Desconocida.

44. AE2. Ceca: Tesalónica. Cronología: Graciano, años 378-383 d. C. A: Cabeza a derecha con diadema de perlas, leyenda: DN GRATIANVS PF AVG. R: Emperador de pie, en la mano izquierda porta victoria sobre globo, con la mano derecha ayuda a levantarse a una mujer arrodillada, delta en el campo derecho, leyenda: REPARATIO REIPVB, en el exergo: SMTES. Peso: 6 g. Referencia: RIC IX, 37a. Procedencia: Hijes.

45. Sestercio. Ceca: Roma. Cronología: Adriano, años 125-128 d. C. A: Cabeza a derecha, leyenda: HADRIANVS [AVGVSTVS]. R: Neptuno a izquierda, leyenda ilegible: [COS III S. C]. Peso: 24 g. Referencia: RIC II, 634 o 635. Procedencia: Desconocida.

46. Follis. Ceca: Indeterminada. Cronología: Maximino II. A: Cabeza a derecha, leyenda: MAXIMINVS N[...]. R: Genio a izquierda, leyenda: GENIO [...]. Peso: 6 g. Procedencia: Desconocida.

47. Antoniniano. Ceca: Roma. Cronología: Galieno. A: Cabeza radiada a derecha, leyenda: GALLIENVS AVG. R: Marte a izquierda porta en la mano derecha una rama de olivo, en la izquierda escudo y lanza, leyenda: MARTI PACIFERO. Peso: 2 g. Referencia: RIC VA, 236. Procedencia: Desconocido.

48. Medio centenional?. Ceca: Indeterminada. Cronología: Siglo IV d. C. A: Cabeza a derecha, muy deteriorada. R: Emperador a caballo combatiendo a un enemigo a derecha. Peso: 2 g. Procedencia: Desconocida.

49. Fracción radiada. Ceca: Cycicus. Cronología: 295-299 d. C. A: Cabeza radiada a derecha, leyenda: IMP CMA MAXIMIANVS PF AVG. R: Emperador con vestimenta militar recibe la victoria de Júpiter, leyenda: CONCORDIA MILITVM y en el centro KD. Peso: 2 g. Referencia: RIC VI, 16 b. Procedencia: Alaminos.

50. Antoniniano. Ceca: Roma. Cronología: Galieno 260-268 d. C. A: Cabeza radiada a derecha, leyenda muy deteriorada: IMP GALLIENVS AVG. R: Grifo a izquierda, le- 
yenda: APPOLINI CONS AVG. Peso: 2 g. Referencia: RIC VA, 165. Procedencia: Desconocida.

51. Maiorina. Ceca: Indeterminada. Cronología: Graciano, años 378-383 d. C. A: Cabeza con diadema de perlas a derecha, leyenda: D N GRATIANVS P F AVG. R: Graciano ayuda a levantarse a mujer, en la mano derecha porta victoria sobre globo, leyenda: REPARATIO-REIPVB, en el exergo: LUGS. Peso: 4 g. Referencia: RIC IX, 28. Procedencia: Hijes.

52. Maiorina. Ceca: Antioquía. Cronología: Teodosio. A: Cabeza del emperador a derecha, leyenda: D N THEODOSIVS P F AVG. R: Emperador de pie a derecha, portando estandarte y globo, leyenda: GLORIA ROMANORVM, en el exergo: ANTA. Peso: 5'5 g. Referencia: RIC IX, 68b. Procedencia: Desconocida.

53. Follis. Ceca: Indeterminada. Cronología: Constantino I. A: Cabeza a derecha, leyenda: CONSTANTINUS AVG. R: Puerta de campamento, leyenda: PROVIDENTIAE AVGG, exergo ilegible. Peso: 4 g. Procedencia: Checa $n^{\circ} 38$.

54. As. Ceca: Titiakos. Cronología: Segunda mitad siglo II a. C. A: Cabeza a derecha, detrás signo ti. R: Jinete lancero, debajo leyenda: titiakos. Peso: 8 g. Referencia: Villaronga 1994: 294, $\mathrm{n}^{\circ}$ 2. Procedencia: Desconocida.

55. Follis. Ceca: Roma. Cronología: Constantino I 315 d. C. A: Cabeza a derecha con coraza, leyenda: IMP CONSTANTINVS P F AVG. R: Sol a izquierda, en la mano izquierda porta el orbe, mientras alza la derecha, a su izquierda $\mathrm{C}$, a su derecha $\mathrm{S}$, leyenda: SOLI INVICTO COMITI, en el exergo RP. Peso: 3'6 g. Referencia: RIC VII, 40. Procedencia: Desconocida.

56. Follis. Ceca: Siscia. Cronología: 334-335 d. C. A: Cabeza a derecha, con coraza, leyenda: FL CONSTANTIS BEA C. R: Dos soldados con escudo y lanza, entre ellos dos estandartes, leyenda: GLORIA EXERCITVS, en el exergo: ASIS. Peso: 2'5 g. Referencia: RIC VII, 238. Procedencia: Desconocida.

57. AE 3. Ceca: ¿Arles?. Cronología: Constantino ¿330-335 d. C.?. A: Cabeza a derecha con diadema y coraza, leyenda muy deteriorada: CONSTANTINVS MAX AVG. R: Dos soldados con lanza y escudo, entre ellos dos estandartes, leyenda muy deteriorada: [¿GLORIA EXERCITVS?]. Peso: 2'5 g. Referencia: ¿RIC VII, 364?. Procedencia: Desconocida.

58. Follis. Ceca: ¿? Cronología: Constancio I. A: Cabeza a derecha, leyenda: IMP CONSTANTIVS P F AVG. R: Genio a izquierda, portando pátera y cornucopia, leyenda: GENIO[...]. Peso: 4 g. Procedencia: Desconocida.

59. As. Ceca: Sekaisa. Cronología: Primera mitad del siglo I a. C. A: Cabeza a derecha con delfín delante y otro detrás. R: Jinete lancero a derecha, debajo de línea leyenda: sekaisa. Peso: 8 g. Referencia: Villaronga 1994: 236, $\mathrm{n}^{\mathrm{o}}$ 42. Procedencia: Desconocida.

60. Follis. Ceca: Arles. Cronología: Constantino I, años 317-318 d. C. A: Cabeza laureada a derecha, leyenda: IMP CONSTANTINVS P F AVG. R: Sol a izquierda con globo 


\section{EMILIO GAMO PAZOS \\ LA COLECCIÓN NUMISMÁTICA DEL ANTIGUO MUSEO DE GUADALAJARA (1838-1902)}

en la mano izquierda, leyenda: SOLI IN-VI-CTO COMITI, a los lados S C, en el exergo: SARL. Peso: 4 g. Referencia: RIC VII, 145. Procedencia: Desconocida.

61. Bronce. Cronología: Bajoimperial. A: Cabeza a derecha, leyenda ilegible. R: Muy deteriorado. Peso: 4 g. Procedencia: Desconocida.

62. As. Ceca: Indeterminada. Cronología: Siglos II-I a. C. A: Cabeza a derecha. R: Jinete lancero a derecha, debajo leyenda ilegible. Peso: 8 g. Procedencia: Desconocida.

63. As. Ceca: Segobriga. Cronología: Calígula. A: Cabeza laureada a izquierda, leyenda: C CAESAR AVG GERMANICUS [IMP]. R: Corona de roble y dentro leyenda: SEGO/BRIGA. Peso: 10 g. Referencia: Ripollès 2010: $n^{\circ} 476$. Procedencia: Checa $n^{\circ}$ 22.

64. As. Ceca: Roma. Cronología: Claudio. A: Cabeza a izquierda, leyenda: TI CLAVDIVS CAESAR AVG PM TR P IMP [...?]. R: Minerva a derecha con lanza y escudo, leyenda: S. C. Peso: 10 g. Referencia: RIC I, 100 o 116. Procedencia: ¿Checa 2829 ?.

65. AE. Cronología: ¿Trajano?. A: Cabeza a derecha. R: Figura humana muy deteriorada. Peso: 14 g. Procedencia: Desconocida.

66. AE. Cronología: Altoimperial. A: Cabeza a derecha, leyenda ilegible. R: Muy deteriorado. Peso: 10 g. Procedencia: Desconocida.

67. As. Ceca: ¿Augusta Emerita?. Cronología: Tiberio. A: Cabeza a izquierdas, leyenda: TI[....]IMP. R: Totalmente deteriorado. Peso: 10 g. Referencia: Ripollès 2010: $\mathrm{n}^{\circ} 42 \mathrm{o}$ 45 o 47?. Procedencia: Desconocida.

68. As. Ceca: Indeterminada, posible hispanorromana. Cronología: ¿Tiberio?. A: Cabeza a izquierdas, leyenda ilegible. R: Totalmente deteriorado. Peso: 8 g. Procedencia: Desconocida.

69. As?. Cronología: Altoimperial. A: Cabeza a derecha, leyenda ilegible. R: Totalmente deteriorado. Peso: 10 g. Procedencia: Desconocida.

70. As. Ceca: Indeterminada (Hispánica). Cronología: Tiberio. A: Cabeza a derecha, leyenda: [...]DIVI AVGV[...]. R: Deteriorada. Peso: 10 g. Procedencia: Desconocida.

71. As?. Cronología: Altoimperial. A: Cabeza a izquierda, leyenda ilegible. R: Muy deteriorado. Peso: 8 g. Procedencia: Desconocida.

72. As. Ceca: Roma. Cronología: Claudio. A: Cabeza a izquierda, leyenda: TI CLAVDIVS CAESAR AVG PM TR P IMP [...?]. R: Minerva a derecha con lanza y escudo, leyenda: S. C. Peso: 10 g. Referencia: RIC I, 100 o 116. Procedencia: ¿Checa 28-29?.

73. As?. Cronología: ¿Altoimperial?. A: Cabeza a izquierda, leyenda ilegible. R: Totalmente deteriorado. Peso: 12 . Procedencia: Desconocida.

74. As?. Cronología: Altoimperial. A: Cabeza a derecha, leyenda ilegible. R: Muy deteriorado. Peso: $10 \mathrm{~g}$. Procedencia: Desconocida.

75. As. Cronología: ¿Lucio Vero 162-163 d. C.?. A: Cabeza laureada a derecha, leyenda muy deteriorada: [IMP. CAES. L. AVREL. VERVS AVG.?]. R: Fortuna sentada a la 


\section{EMILIO GAMO PAZOS \\ LA COLECCIÓN NUMiSMÁTICA DEL ANTIGUO MuSEO DE GUADALAJARA (1838-1902)}

izquierda, leyenda muy deteriorada: [FORT. RED. TR. POT. III. COS. II, S. C.?]. Peso: 10 g. Referencia: RIC III, 1351?. Procedencia: Desconocida.

76. As. Ceca: Tarraco. Cronología: Augusto, Cayo y Lucio (2 a. C.-4 d. C.). A: Cabeza laureada a derecha, leyenda: [IMP CAES AVG TR POT PON MAX P P]. R: Cabezas enfrentadas de Cayo y Lucio, leyenda: [C-V-T/ C L CAES/ AVG F]. Peso: 7 g. Referencia: Ripollès 2010: $\mathrm{n}^{\circ} 210$. Procedencia: Checa $\mathrm{n}^{\circ} 18$.

77. As?. Cronología: Altoimperial. A: Cabeza a izquierda, leyenda ilegible. R: Figura humana muy deteriorada, a ambos lados leyenda: S. C. Peso: 7 g. Procedencia: Desconocida.

78. As?. Cronología: ¿Adriano?. A: Cabeza laureada a derecha, leyenda ilegible. R: Totalmente deteriorado. Peso: $10 \mathrm{~g}$. Procedencia: Desconocida.

79. As. Ceca: Indeterminada, posible hispanorromana. Cronología: ¿Tiberio?. A: Cabeza a izquierdas, leyenda ilegible. R: Totalmente deteriorado. Peso: 10 g. Procedencia: Desconocida.

80. As. Ceca: Calagurris. Cronología: Tiberio. A: Cabeza laureada a derecha, contramarca águila, leyenda: [TI CAESAR DIVI AVG F AVG(VS)TVS]. R: Toro a derecha, leyenda: MCI/ C. CELERE/ G. RECTO/ II/ VIR. Peso: 12 g. Referencia: Ripollès 2010: 450. Procedencia: Probablemente Checa, $\mathrm{n}^{\circ} 20$.

81. AE. Cronología: ¿Marco Aurelio?. A: Cabeza a derecha, leyenda ilegible. R: Figura humana muy deteriorada. Peso: 10 g. Procedencia: Desconocida.

82. As. Ceca: Indeterminada, hispánica meridional. Cronología: ¿Siglos II-I a. C?. A: Cabeza a derecha. R: Dos atunes, leyenda ilegible. Peso: 8 g. Procedencia: Desconocida.

83. AE. Cronología: Indeterminada. A: Cabeza a izquierda. R: Muy deteriorado. Peso: 8 g. Procedencia: Desconocida.

84. AE. Ceca: Indeterminada. Cronología: ¿Altoimperial?. A: Cabeza a izquierdas, leyenda ilegible. R: Figura humana, muy deteriorada. Peso: 8 g. Procedencia: Desconocida.

85. AE. Cronología: ¿Domiciano?. A: Cabeza a derecha, leyenda: [IMP CAES DOMIT AVG?] GERM [...]. R: Figuras humanas, muy deterioradas. Peso: 10 g. Procedencia: Desconocida.

86. As. Ceca: Roma. Cronología: Domiciano. A: Cabeza a derecha, leyenda: IMP CAES DIVI VESP F DOMITIAN[...]. R: Minerva a izquierda, a los lados S C, leyenda ilegible. Peso: 8 g. Referencia: RIC II (2007), 89. Procedencia: Desconocida.

87. As?. Cronología: ¿Altoimperial?. A: Cabeza a izquierdas, leyenda ilegible. R: Totalmente deteriorado. Peso: 8 g. Procedencia: Desconocida.

88. As?. Cronología: ¿Altoimperial?. A: Cabeza a derecha, leyenda ilegible. R: Muy deteriorado. Peso: 8 g. Procedencia: Desconocida.

89. As. Ceca: Roma. Cronología: Calígula, años 37-38 d. C. A: Cabeza a izquierda, leyenda: C. CAESAR AVG. GERMANICVS PON. M. TR. POT. R: Vesta sentada a iz- 


\section{EMILIO GAMO PAZOS \\ LA COLECCIÓN NUMiSMÁTICA DEL ANTIGUO MuSEO DE GUADALAJARA (1838-1902)}

quierda, leyenda: VESTA/ S. C. Peso: 10 g. Referencia: RIC I, 38. Procedencia: Desconocida.

90. As?. Cronología: ¿Altoimperial?. A: Cabeza a izquierdas, leyenda ilegible. R: Totalmente deteriorado. Peso: 10 g. Procedencia: Desconocida.

91. As?. Cronología: ¿Adriano?. A: Cabeza a derecha, leyenda ilegible. R: Figura humana muy deteriorada. Peso: 8 g. Procedencia: Desconocida.

92. AE. Ceca: Indeterminada. Cronología: Indeterminada. A: Totalmente deteriorado. R: Totalmente deteriorado. Peso: 6 g. Procedencia: Desconocida.

93. AE. Cronología: Indeterminada. A: Cabeza. R: Totalmente deteriorado. Peso: 6 g. Procedencia: Desconocida.

94. As?. Cronología: ¿Altoimperial?. A: Cabeza a izquierdas, leyenda ilegible. R: Totalmente deteriorado. Peso: 8 g. Procedencia: Desconocida.

96. As?. Cronología: ¿Altoimperial?. A: Cabeza a derecha. R: Totalmente deteriorado. Peso: 8 g. Procedencia: Desconocida.

103. Sestercio. Cronología: Alejandro Severo. A: Cabeza a derecha, leyenda: [IMP CAES M AVR SEV ALEXANDER AVG]. R: Júpiter sentado a izquierda, con victoria en la mano, leyenda ilegible. Peso: 12'5 g. Referencia: Probable RIC IVB, 560. Procedencia: Desconocida.

104. As. Ceca: Roma. Cronología: Calígula, aunque es alusiva a Agrippa. A: Cabeza de Agrippa a izquierda, con corona rostral, leyenda: M AGRIPPA L F COS III. R: Neptuno a izquierda, en la mano derecha porta un pequeño delfín, en la mano derecha, en la mano izquierda un tridente. A ambos lados leyenda: S C. Peso: 10 g. Referencia: RIC I, 58. Procedencia: Desconocida.

\section{CONCLUSIONES.}

El estudio de las colecciones antiguas en combinación con la información procedente de archivos permite en este caso aproximarnos a la contextualización de materiales arqueológicos procedentes de hallazgos antiguos. Pero por otra parte arroja luz sobre los comienzos de la arqueología romana en España, aportando datos acerca de las excavaciones que en el siglo XIX se realizaron en yacimientos como la villa romana de "Los Arroyos" (Hijes) o "Castil Griegos" (Checa). Yacimientos sobre los que recientemente se han realizado prospecciones y excavaciones arqueológicas cuyos resultados se ven complementados por los datos procedentes de excavaciones antiguas (Cerdeño y Gamo 2013; Martínez y de la Torre 2008).

Aunque el origen de parte del conjunto numismático es desconocido, creemos que este viene a aportar datos interesantes para futuras investigaciones 


\section{EMILIO GAMO PAZOS \\ LA COLECCiÓN NUMiSMÁtiCA DEL ANTIGUO MuSEO DE GUADALAJARA (1838-1902)}

acerca de la circulación monetaria en esta área. Zona que como se ha señalado es parca en hallazgos numismáticos publicados.

Esta colección de monedas muestra coincidencias con otros conjuntos numismáticos publicados de la provincia de Guadalajara. Muy interesante es la notable presencia de monedas oriundas de cecas del valle del Ebro con signario paleohispánico e hispanorromanas que viene a confirmar la fuerte relación entre ambos territorios (Gozalbes 2008: 204). Esta vinculación de los valles del Henares, Tajuña y Tajo con el valle del Ebro tiene su precedente en época prerromana y se constata ya en el período Celtibérico Antiguo (Cerdeño y Sagardoy 2007). En la época romana republicana las formas de la cerámica romana de importación (barniz negro y ánforas) parecen asociarse en la mayoría de los casos a redes de distribución vinculadas al valle del Ebro (Gamo y Azcárraga 2012) y ello es interesante porque la existencia de contactos comerciales entre los valles del Tajo y el Henares con el medio Ebro se documenta también en la circulación numismática, al igual que la posterior red viaria romana imperial seguirá las mismas rutas.

\section{BIBLIOGRAFÍA.}

Abascal, J. M., 1984: "Numismática romana de Guadalajara en una colección particular", Wad-Al-Hayara, 11: 327-342.

Abascal, J. M., 2002: "La fecha de la promoción colonial de Carthago Nova", Mastia, 1: 21-44.

Aguado, F., 2006: "Museo de Guadalajara: Evolución, situación actual y perspectivas de futuro", Boletín de la Asociación de Amigos del Museo de Guadalajara, 1: 51-67.

Aguilera y Gamboa, E., 1916: Las necrópolis ibéricas, Madrid.

Arenas, J. A., 1999: La Edad de Hierro en el Sistema Ibérico Central, España, British Archaeological Reports, International Series, 780, Oxford.

Baquerizo, C., 1902: Catálogo de los cuadros de pintura, esculturas y monedas existentes en el Museo establecido en el Palacio de la Excelentísima Diputación Provincial, Diputación de Guadalajara, Guadalajara.

Cerdeño, M. L. y Gamo, E., 2013: "Fíbula romana "de rodilla" (Kniefibeln) procedente de Hijes (Guadalajara)", Zephyrus, 72: 175-182.

Cerdeño, M. L. y Sagardoy, T., 2007: La necrópolis celtibérica de Herrería III y IV (Guadalajara), Estudios Celtibéricos, 4, Zaragoza.

De la Fuente, J. J., 1883: "El Museo Provincial de Guadalajara", Boletín de la Real Academia de Bellas Artes de San Fernando, Año 3, Tomo 3: 163-177. 
Gamo, E. y Azcárraga, S., 2012: “Cerámica de barniz negro de época romana republicana en yacimientos celtibéricos y carpetanos de la provincia de Guadalajara", Lucentum, 31: 131-146.

Gómez-Pantoja, J. y López, M. A., 2004: "Los inicios de la arqueología en Guadalajara. Dos notas sobre yacimientos poco conocidos", en Gómez-Pantoja, J. (ed.): Excavando papeles. Indagaciones arqueológicas en los archivos españoles, Guadalajara, Ed. Aache: 153-166.

Gozalbes, E., 2008: “Aspectos numismáticos de Guadalajara en la Antigüedad (Siglos II-I a. C.)", en García-Soto, E.; García, M. A. y Martínez, J. P. (eds.): Actas del Segundo Simposio de Arqueología de Guadalajara, Madrid: 193-207.

López, M. A., 1997: "Un intento frustrado de inventario arqueológico e histórico del siglo XIX. La Comisión de Monumentos de Guadalajara (1844)”, en Mora, G. y Díaz, M., La cristalización del pasado. Génesis y desarrollo del marco Institucional de la Arqueología en España, Málaga.

López, M. A. y García-Risco, M., 1996: "La Comisión de Monumentos de Guadalajara (1835-1939). Breve reseña histórica e inventario de fuentes”, en La investigación y las fuentes documentales de los archivos, Guadalajara: 235-240.

Martínez, J. P. y de la Torre, J. I., 2008: "La necrópolis celtibérica de Puente de la Sierra (Checa, Guadalajara)", en García-Soto, E.; García, M. A. y Martínez, J. P., (eds.), Actas del II Simposio de Arqueología de Guadalajara, Madrid: 175-193.

Meier, J., 1999: Comisión de Antigüedades de la Real Academia de la Historia. CastillaLa Mancha, Catálogo e Indices, Real Academia de la Historia, Madrid.

RIC I=Sutherland, C. H. V. y Carson, R. A. G., 1984: The Roman Imperial Coinage, Volume I, From 31 BC to AD 69, London.

RIC II=Mattingly, H. y Sydenham, E. A., 1972: The Roman Imperial Coinage, Volume II, Vespasian to Hadrian, London.

RIC II (2007)= Carradice, I. y Buttrey, T. V., (2007): The Roman imperial coinage, Volume II, part 1, From AD 69-96, Vespasian to Domitian (Second fully revised Edition), Spink, London.

RIC III=Mattingly, H. y Sydenham, E. A., 1930: The Roman Imperial Coinage, Volume III, Antoninus Pius to Commodus, London.

RIC IVA=Mattingly, H. y Sydenham, E. A., 1936: The Roman Imperial Coinage, Volume IV, Part I, Pertinax to Geta, London.

RIC IVB=Mattingly, H. y Sydenham, E. A., 1938: The Roman Imperial Coinage, Volume IV, Part II, Macrinus to Pupienus, London.

RIC VA=Mattingly, H. y Sydenham, E. A., 1972: The Roman Imperial Coinage, Volume $V$, Part I, London.

RIC VB=Mattingly, H. y Sydenham, E. A., 1972: The Roman Imperial Coinage, Volume $V$, Part II, London. 
RIC VI=Sutherland, C. H. V. y Carson, R. A. G., 1967: The Roman Imperial Coinage, Volume VI, From Diocletian's reform (A. D. 294) to the death of Maximinus (A. D. 313), London.

RIC VII=Brunn, P., 1966: The Roman Imperial Coinage, Volume VII, Constantine and Licinius AD 313-337, London.

RIC VIII=Kent, J. P. C., 1981: The Roman Imperial Coinage, Volume VIII, The family of Constantine AD 337-364, London.

RIC IX=Pearce, J. W. E., 1951: The Roman Imperial Coinage, Volume IX, Valentinian ITheodosius I, London.

Ripollès, P. P., 2010: Las acuñaciones provinciales romanas de Hispania, Bibliotheca Numismatica Hispana 8, Real Academia de la Historia, Madrid.

Sánchez Portocarrero, D., 1641: Antigüedad del noble y muy Leal Señorio de Molina. Facsímil de la edición de 1641, Estudio preliminar sobre el autor y obra por A. Herrera, Ed. Aache, Guadalajara.

Uhagón, F. R., 1893: “Antigüedades romanas de la Alcarria”, Boletín de la Real Academia de la Historia, 23: 346-350.

Untermann, J., 1997: Monumenta Linguarum Hispanicarum. IV Die tartessischen, keltiberischen und lusitanischen Inschriften, Wiesbaden.

Vidal, J.M., 1981: “Aportación a la circulación monetaria en Arcobriga, Aguilar de Anguita y Luzaga", Acta Numismática, 11: 67-76.

Villaronga, L., 1994: Corpus Nummum Hispaniae ante Augusti Aetatem, Madrid. 
EMILIO Gamo Pazos

LA COLECCIÓN NUMismática DEL ANTIGUO MuSEO DE GUADALAJARA (1838-1902)

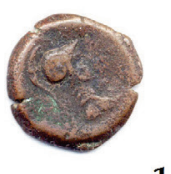

1

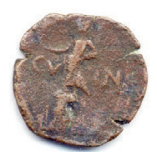

(1)
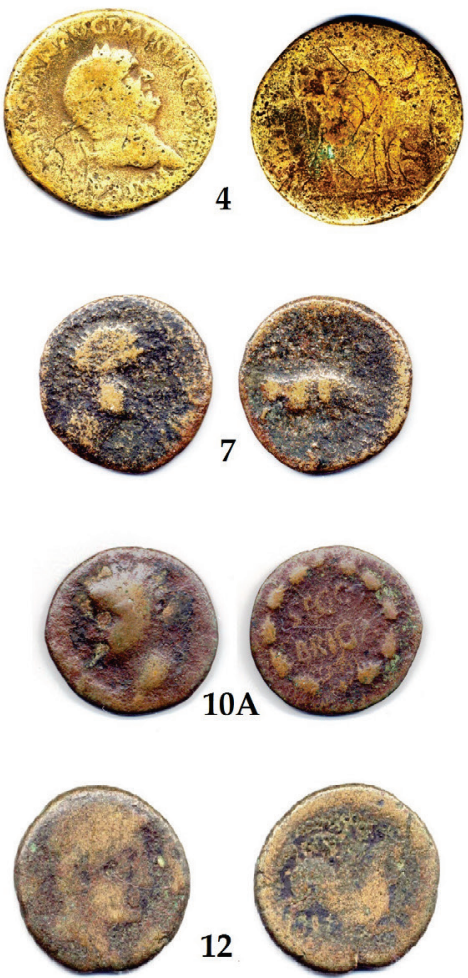

12
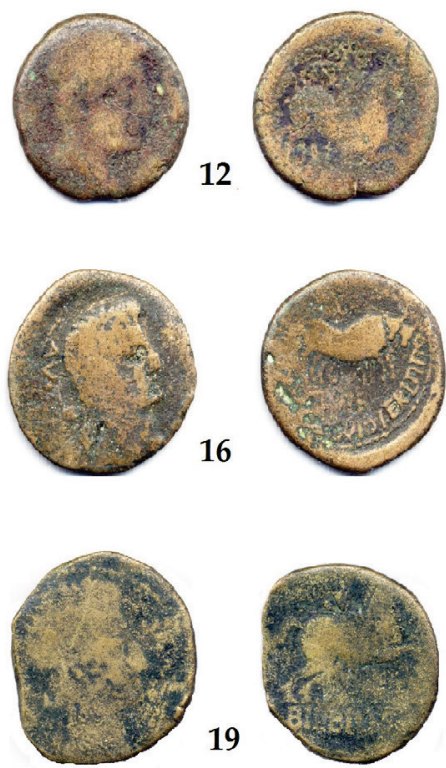

19

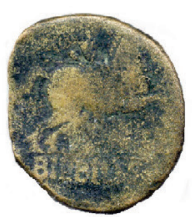

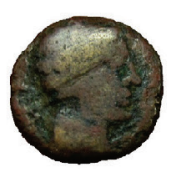

2
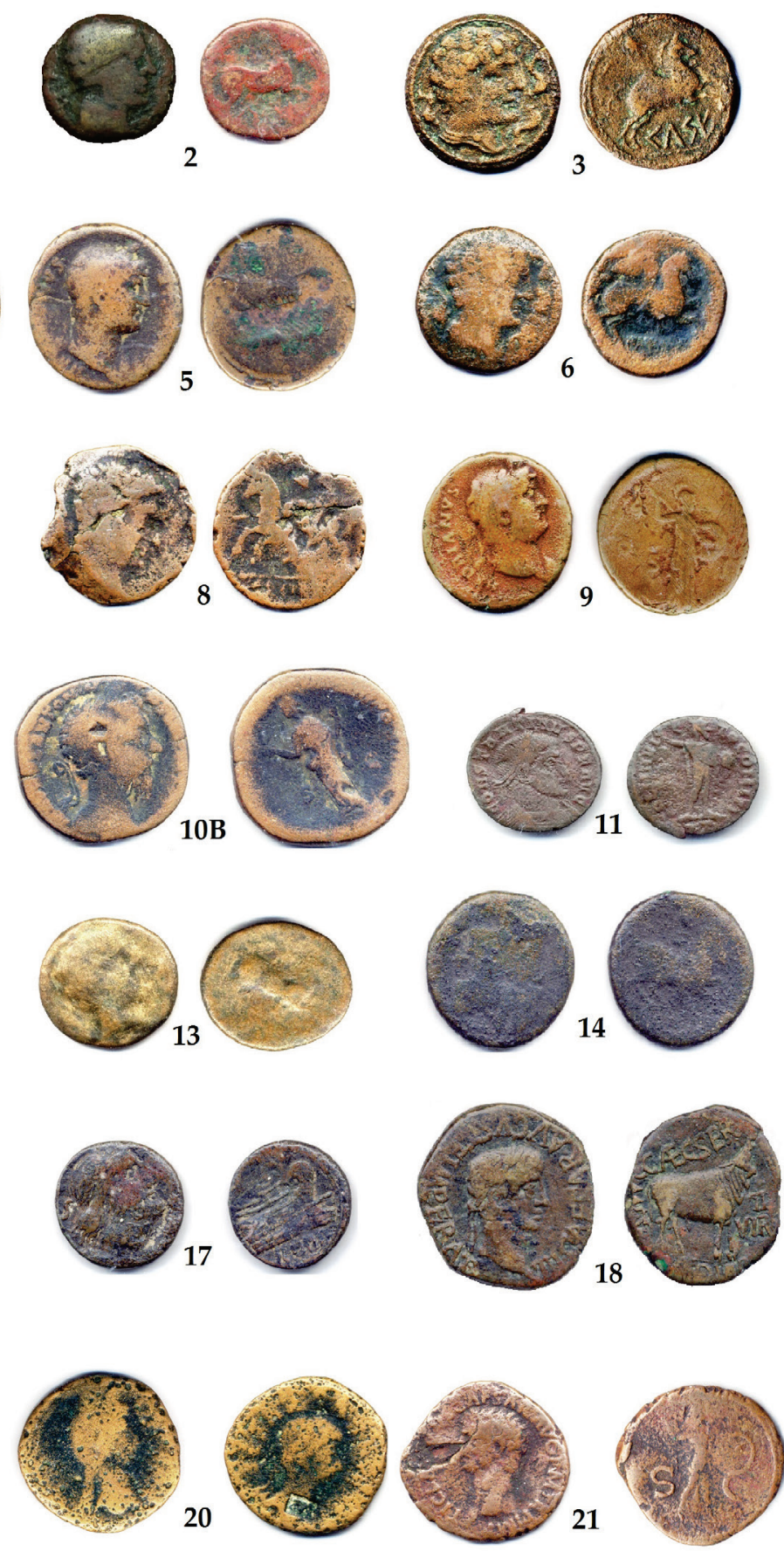

21

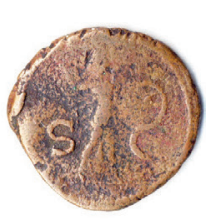


Emilio Gamo Pazos

LA COLECCIÓN NUMISMÁTICA DEL ANTIGUO MUSEO DE GUADALAJARA (1838-1902)

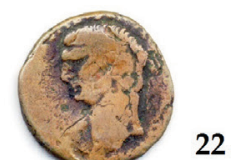

22
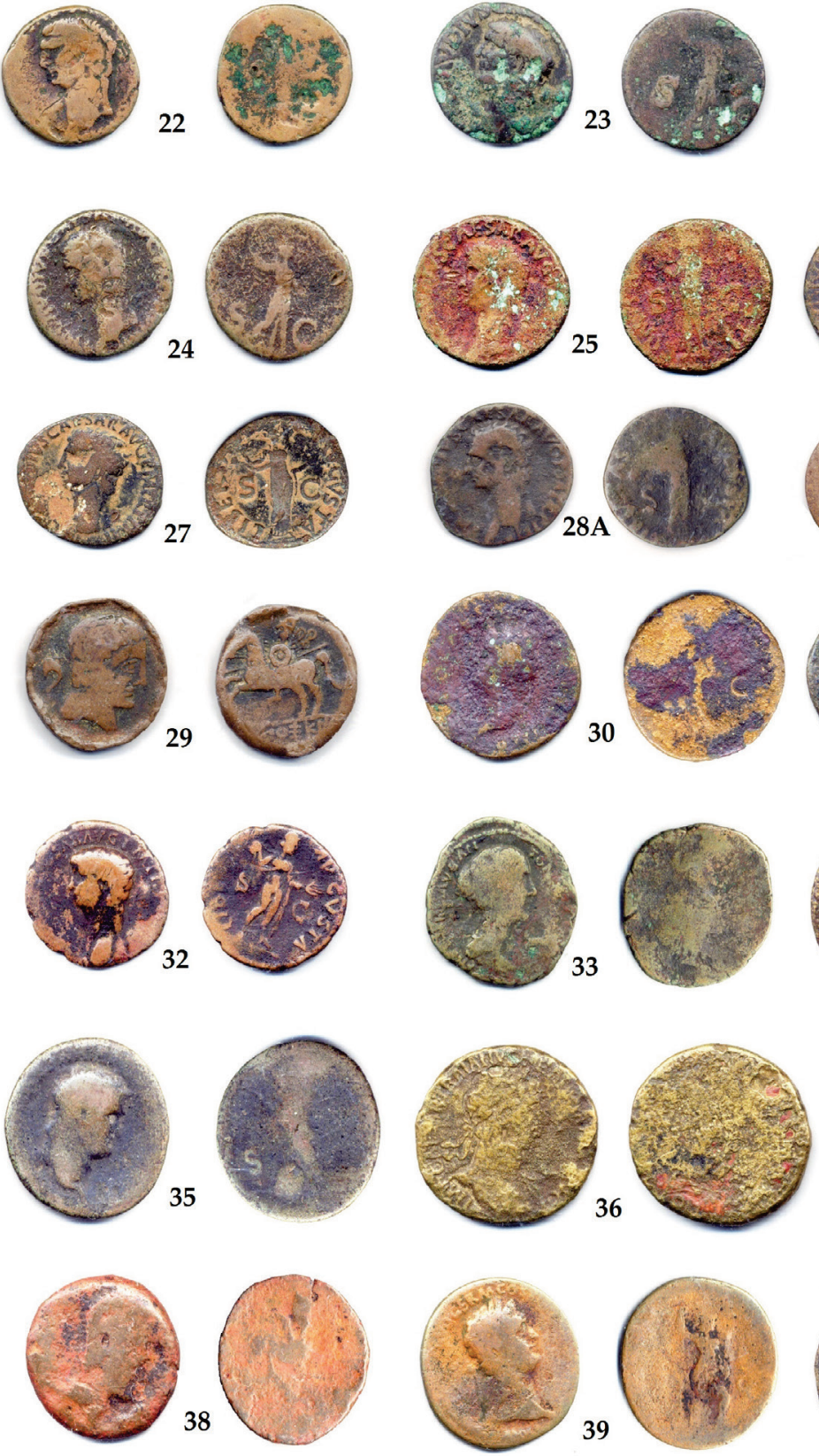
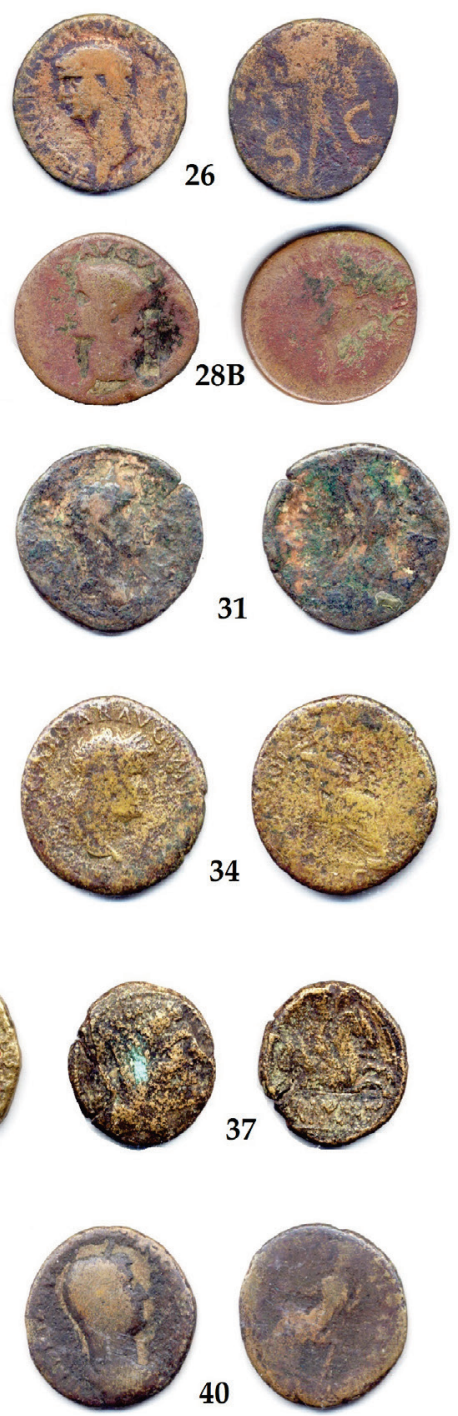

40

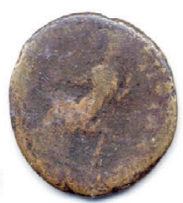


Emilio Gamo Pazos

LA COLECCIÓN NUMISMÁTICA DEL ANTIGUO MUSEO DE GUADALAJARA (1838-1902)

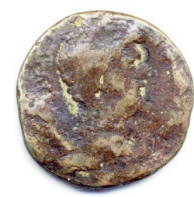

41
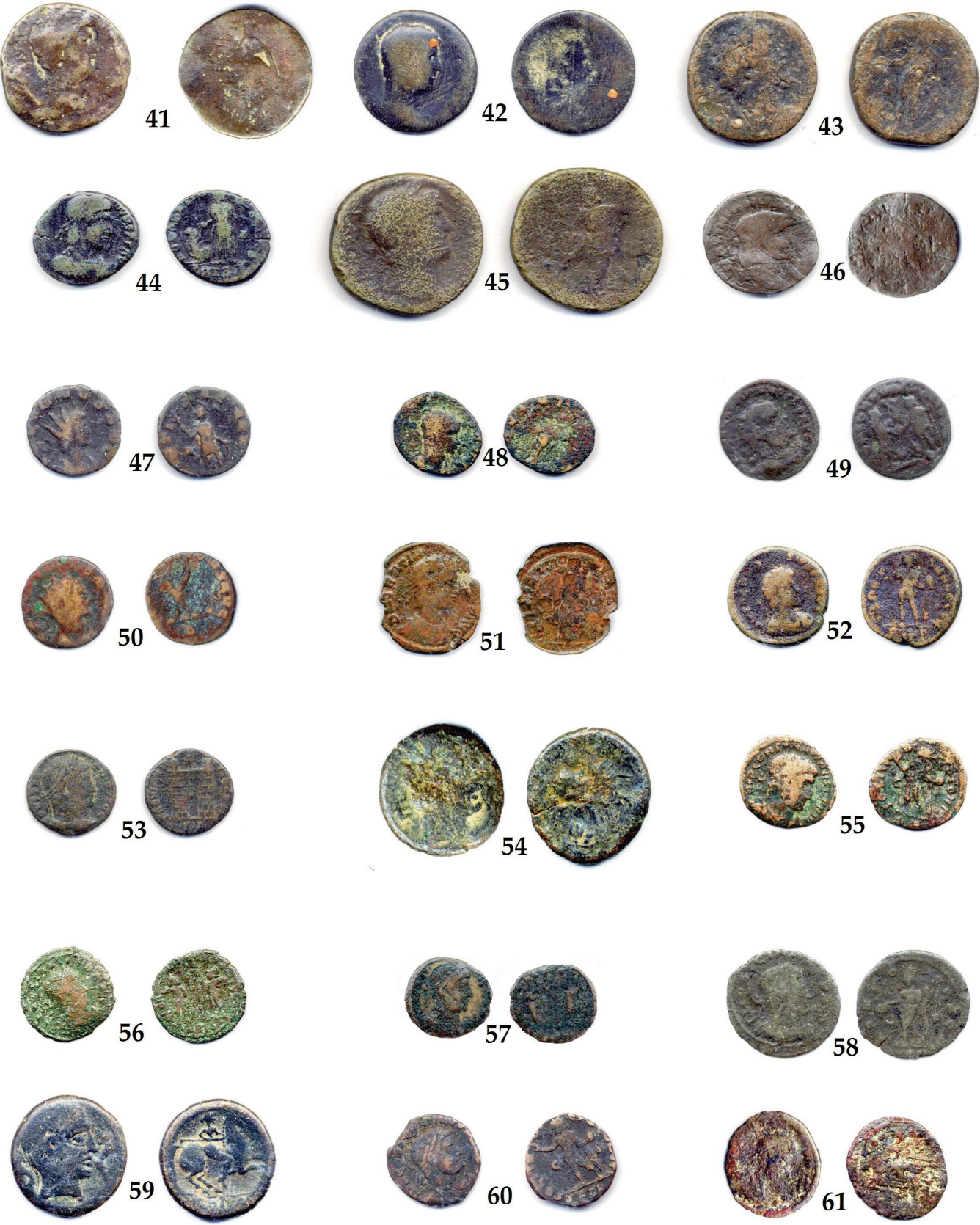
Emilio Gamo Pazos

LA COLECCIÓN NUMISMÁTICA DEL ANTIGUO MUSEO DE GUADALAJARA (1838-1902)
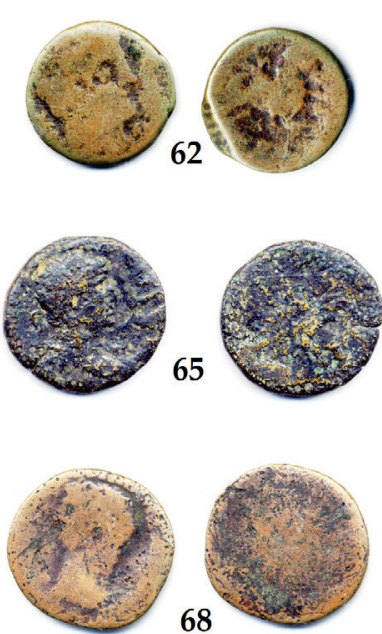

68
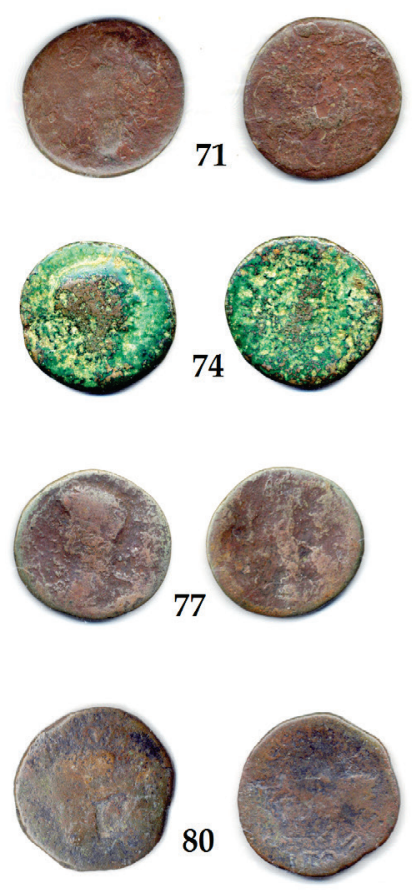
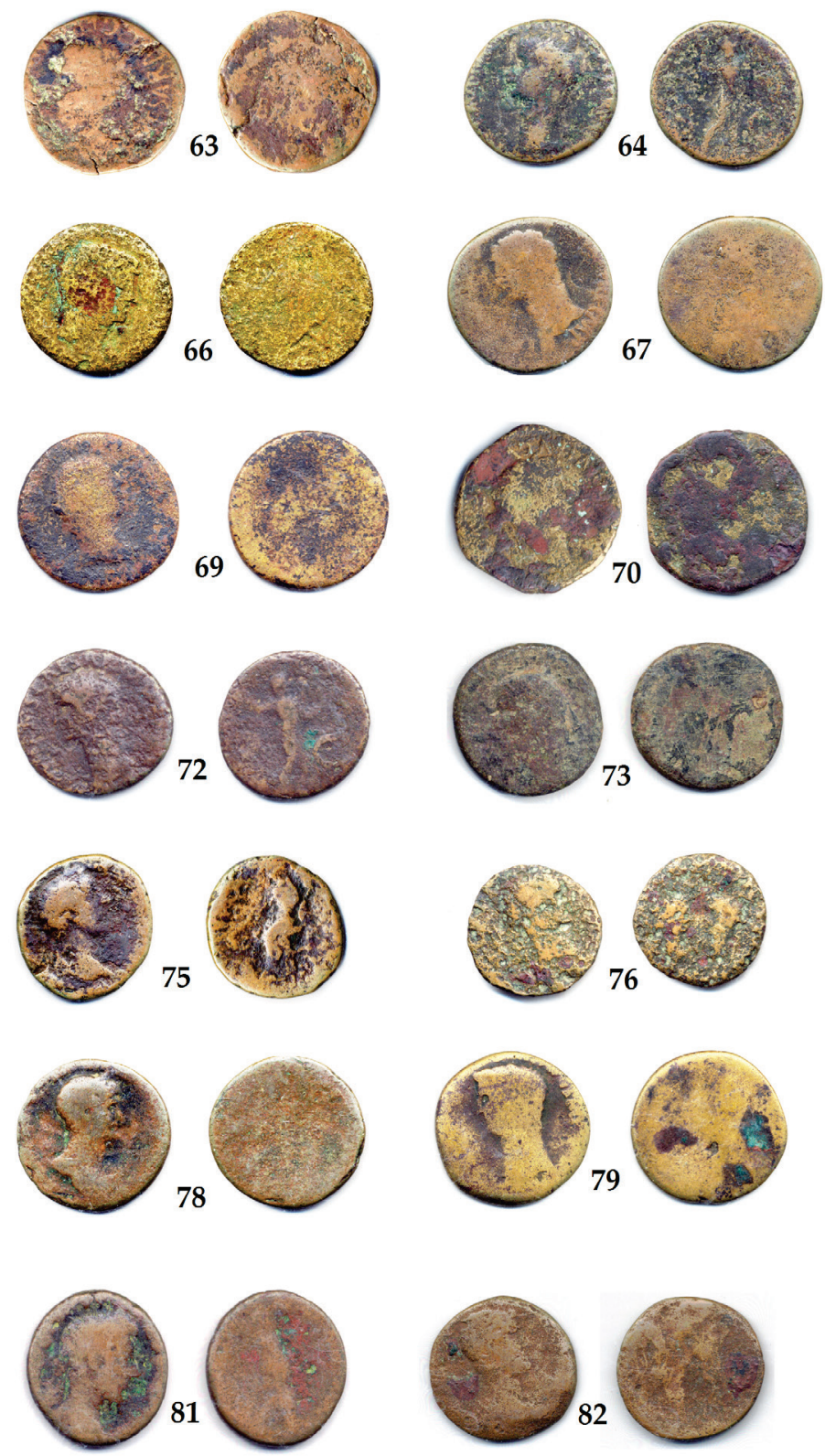
EMILIO Gamo Pazos

LA COLECCIÓN NUMISMÁTICA DEL ANTIGUO MUSEO DE GUADALAJARA (1838-1902)
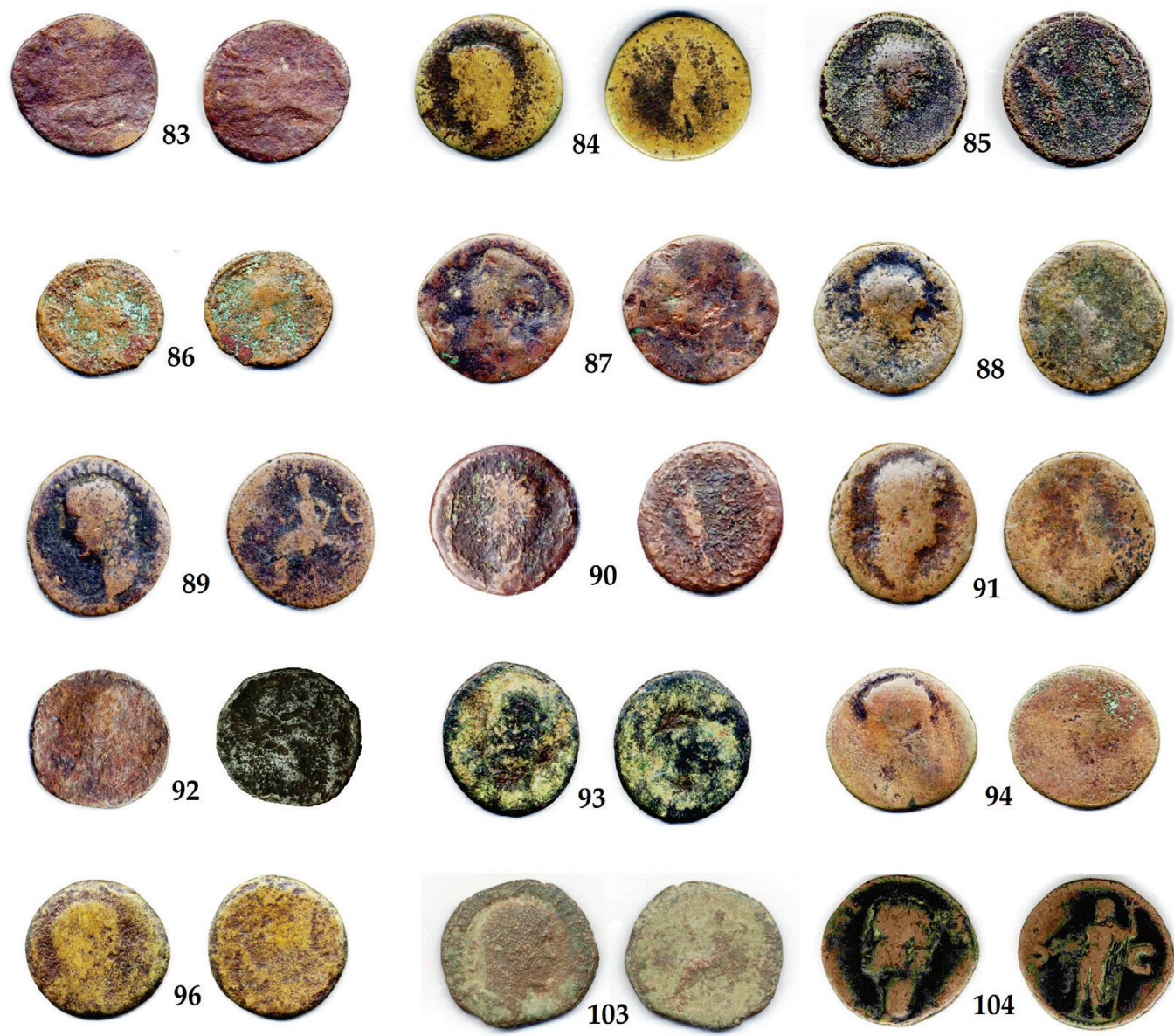